\title{
Implementasi Pembelajaran Bahasa Arab melalui Pendekatan Saintifik di Kelas 1 MI Ar-Rahmah Jabung Kabupaten Malang
}

\author{
Amang Fathurrohman ${ }^{1}$, Luluk Farida ${ }^{1}$, Dewi Anisatuz Zakiyah ${ }^{1}$, Bilghis Lu'luil Malihatus \\ Sya'bah $^{1}$, Sholihatul Atik Hikmawati ${ }^{1}$, Mochamad Hasyim ${ }^{2}$, Hasan Syaiful Rizal ${ }^{2}$ \\ ${ }^{1}$ IAI Sunan Kalijogo Malang, ${ }^{2}$ Universitas Yudharta Pasuruan \\ amangfr@gmail.com, lulukpba@gmail.com,anisazakiyah@yahoo.com, bilqisluluil03@gmail.com, \\ sholihatulhikmawati@gmail.com, hasyim@yudharta.ac.id
}

\author{
Article History: \\ Received: \\ 08-06-2020 \\ Revised: \\ 16-06-2020 \\ Accepted: \\ 30-06-2020

\section{Keywords:} \\ Kurikulum 2013, K13, \\ Pendekatan Saintifik, \\ Pembelajaran Bahasa Arab
}

\begin{abstract}
:
Madrasab Ibtidaiyah Ar-Rahmah Malang is a primary level educational institution in Jabung District of Malang Regency. Since Class 1, students have been introduced to Arabic language lessons using a scientific approach. Through qualitative methods, the results of this study indicate that the implementation of Arabic learning using a scientific approach has been carried out by Madrasah Ibtidaiyah Ar-Rahmah teachers. Various methods are used so that the scientific approach can be achieved properly. However, because they are still in class 1 Madrasah Ibtidaiyah, the emphasis on Arabic is still directed to memorize mufrodat related to everyday themes. So the scientific approach is still not optimal to be implemented in grade 1 students of Madrasah Ibtidaiyah Ar-Rabmah Jabung Malang.
\end{abstract}

\section{Pendahuluan}

Kurikulum merupakan bagian integral dari sistem pembelajaran. Oleh karena itu, maka kurikulum merupakan instrumern utama sebagai dasar pijak untuk mengetahui keberhasilan pembelajaran, baik dari sisi proses maupun hasil. Salah satunya Kurikulum tahun 2013 (K13), yang merupakan penyempurnaan dari kurikulum sebelumnya yakni kurikulum Berbasis Kompetensi dan Kurikulum Tingkat Satuan Pendidikan. ${ }^{1}$

Dalam Kurikulum 2013 ini, pendekatan pembelajaran yang ditetapkan menggunakan pendekatan saintifik yang berlaku untuk semua matapelajaran, termasuk bahasa Arab. Dalam pendekatan saintifik ini memadukan lima unsur dalam satu-kesatuan, yakni: mengamati, menanya, mencoba, mengasosiasikan, dan mengkomunikasikan. ${ }^{2}$ Dasar implementasi ini telah diatur dalam Peraturan Kementrian Pendidikan dan Kebudayaan (Permendikbud) No. 103, Tahun 2014

\footnotetext{
${ }^{1}$ Lihat Kajian Perkembangan Kurikulum dalam Sholihatul Atik Hikmawati, "PENDEKATAN DAN MODELMODEL PENGEMBANGAN KURIKULUM BAHASA ARAB PADA MADRASAH/SEKOLAH DI INDONESIA," Muhadasab: Jurnal Pendidikan Bahasa Arab 2, no. 1 (2019): 203-218.

2 Muhammad Abduh, "Interaksi Pada Pendekatan Saintifik (Kajian Teori Scaffolding)," in Prosiding Seminar Nasional Dan Call for Papers Pendidikan 2017 (PGSD UMS \& HDPGSDI Wilayah Jawa) (Semarang: Program Studi Pendidikan Guru Sekolah Dasar FKIP UMS, 2017), 307-318.
} 
tentang Pembelajaran pada Pendidikan Dasar dan Menengah, Pasal 2, Ayat 8 yang menyatakan bahwa.

Pendekatan saintifik/pendekatan berbasis proses keilmuan sebagaimana dimaksud pada ayat (7) merupakan pengorganisasian pengalaman belajar dengan urutan logis meliputi proses pembelajaran: a. mengamati; b. menanya; c. mengumpulkan informasi/mencoba; d. menalar/mengasosiasi; dan e. mengomunikasikan. ${ }^{3}$

M. Abduh dengan mengutip kajian Reiser menunjukkan bahwa pendekatan saintifik merupakan kegiatan yang membutuhkan komponen interaksi kognitif dan sosial. ${ }^{4}$ Lalu, bagaimana bila dikaitkan dengan pelajaran bahasa Arab?. Moh. Ainin membuat pertanyaan apakah pendekatan ini relevan atau aplicable untuk pembelajaran bahasa Arab bagi siswa yang notabena masih tingkat pemula. Hasil kajiannya menyatakan bahwa pendekatan saintifik kurang relevan dan kurang aplikatif untuk diimplementasikan dalam pembelajaran bahasa Arab. Lebih lanjut, Moh. Aini menyatakan bahwa pembelajaran bahasa, khususnya bahasa Arab memiliki pendekatan tersendiri yang diadopsi baik dari teori linguistik maupun psikologi belajar. Apabila pendekatan saintifik ini dipaksakan untuk diterapkan, maka keterpaksaan itu pada pembelajaran membaca dan menulis. ${ }^{5}$

Berangkat dari latar belakang tersebut, maka kajian ini ingin mengungkap tentang bagaimana proses implementasi pembelajaran bahasa Arab dengan menggunakan pendekatan saintifik pada siswa kelas 1 MI Ar-Rahmah Jabung Malang

\section{Metode}

Metode yang digunakan dalam kajian ini menggunakan kualitatif, objek dan tempat penelitian di Madrasah Ibtidaiyah Ar-Rahmah Jabung Malang yang dilaksanakan pada bulan Maret 2020, teknik pengumpulan data menggunakan interview, observasi, dan dokumentasi, dan teknik analisis data menggunakan pengumpulan data, reduksi data, penyajian data.

\section{Hasil dan Pembahasan}

Madrasah Ibtidaiyah Ar-Rahmah Jabung, adalah salah salah satu lembaga pendidikan dasar yang beralamat di Jl. Sidodadi, Dusun Bando, Sukolilo, Jabung, Malang. Salah satu mata pelajaran yang dikembangkan di lembaga tersebut adalah bahasa Arab yang telah disampaikan

\footnotetext{
${ }^{3}$ Menteri Pendidikan dan Kebudayaan Republik Indonesia, Peraturan Kementrian Pendidikan Dan Kebudayaan No. 103 Tabun 2014 Tentang Pembelajaran Pada Pendidikan Dasar Dan Menengah (Indonesia, 2014).

4 Abduh, "Interaksi Pada Pendekatan Saintifik (Kajian Teori Scaffolding)." Lihat juga Brian J Reiser, "Scaffolding Complex Learning: The Mechanisms of Structuring and Problematizing Student Work," The Journal of the Learning sciences 13 , no. 3 (2004): 273-304.

${ }^{5}$ Moh Ainin, "IMPLEMENTASI PENDEKATAN SAINTIFIK DI ERA KURIKULUM 13 DALAM PEMBELAJARAN BAHASA ARAB: RELEVANKAH?," in Prosiding Konfererensi Nasional Bahasa Arab, vol. 3 (Kota Malang: Sastra Arab Universitas Negeri Malang, 2017), 377-385.
} 
sejak kelas 1. Sebagaimana umumnya lembaga MI di Indonesia, Pembelajaran Bahasa Arab juga mengikuti kurikulum yang telah ditetapkan oleh Pemerintah, baik mulai dari kelas 1 sampai kelas 6.

Madrasah Ibtidaiyah Ar-Rahmah telah mengimplementasikan kurikulum K13 dengan pendekatan saintifik, yakni memadukan lima unsur dalam satu kesatuan, diantaranya: mengamati, menanya, mencoba, mengasosiasikan, dan mengkomunikasikan. Oleh karena itu, maka guru pelajaran Bahasa Arab dituntut untuk mengembangkan berbagai varian metode dan media dalam proses pembelajarannya agar pendekatan saintifik dapat berjalan dengan maksimal, sebagaimana diungkapkan oleh Nabila Nauliana sebagai berikut:

Pendekatan yang digunakan dalam pembelajaran Bahasa Arab menggunakan pendekatan saintifik karena menggunakan K13, sedangkan kalau metodenya bermacam-macam, ada yang menggunakan metode discover learning, inquiry, demonstrasi atau ceramah.

Kalau media macem-macem ya, melihat materinya ada yang pakai Audiovisual, Audiolingual, visual misalnya anak- anak kita perdengarkan lagu yang berhubungan dengan Bahasa Arab seperti kemarin itu saja ajari lagu Balonku yang saya ubah menjadi nama-nama hari. ${ }^{6}$

Dari paparan di atas diketahui bahwa guru Bahasa Arab di MI Ar-Rahmah menggunakan beragam metode, baik itu discover learning, inquiry, demonstrasi atau ceramah. Serta didukung dengan beragam media interaktif Audiovisual, Audiolingual, visual. Terkait Lembar Kerja Siswa, Guru Bahasa Arab di Ar-Rahmah tidak menempatkan LKS sebagai media utama dalam proses pembelajaran, namun lebih difungsikan sebagai sebagai pendamping penguatan materi.

Dengan demikian, dalam proses pembelajaran Bahasa Arab, Guru membuat inovasi pembelajaran agar materi yang disampaikan dapat diserap dengan baik oleh para siswanya, salah satunya dengan melakukan modifikasi lagu yang sudah tidak asing bagi anak-anak kelas 1, yang berjudul Balonku, untuk diubah menjadi materi pelajaran nama-nama hari.

Inovasi yang dilakukan oleh guru ini mendapat respon yang positif dari siswa. Mereka semakin antusian melaksanakan pembelajaran Bahasa Arab, karena pembelajaran tidak hanya dilakukan dengan metode ceramah, namun juga dilakukan variasi metode yang mampu menarik minat siswa untuk mengenal mufrodat-mufrodat yang berhubungan dengan materi tersebut melalui lagu. Dengan cara terebut, para siswa lebih cepat menghafal dan memahami materi yang disampaikan.

Kebanyakan siswa sangat antusias sekali karena anak kelas 1 itu sering kali satu minggu ini dikasih materi trus minggu depannya lagi kita kasih lagu yang berhubungan dengan materi tersebut, jadi mereka cepat hafal dengan materinya, apalagi dengan mufrodat. ${ }^{7}$

\footnotetext{
${ }^{6}$ Interview dengan Nabila Nauliana, Guru MI Ar-Rahmah Jabung Malang, 2 Maret 2020

${ }^{7}$ Interview dengan Nabila Nauliana, Guru MI Ar-Rahmah Jabung Malang, 2 Maret 2020
} 
Namun begitu, implementasi pembelajaran bahasa Arab di MI Ar-Rahmah Jabung Malang juga menemui hambatan dan kendala, baik alokasi waktu yang terbatas, kemampuan kapasitas siswa yang berbeda-beda, serta pemahaman siswa terkait kemanfaatan yang diperoleh dalam belajar bahasa Arab.

Probem yang ditemukan ketika pembelajaran Bahasa Arab IQ nya anak-anak yang rendah itu masih sangat sulit sekali untuk menghafal.

Pendekatan yang saya gunakan itu biasanya saya pancing dengan cerita-cerita yang sangat menarik, seperti contohnya pernah saya ceritai kalau mereka itu belajar Bahasa Arab biar bisa ke Mekkah. Kalau naik Haji biar bisa berkomunikasi dengan orang Arab. Jadi mereka menjadi antusias dan semangat untuk belajar Bahasa Arab.

Data di atas menunjukkan bahwa dalam pembelajaran bahasa Arab masih banyak dijumpai anak-anak yang memiliki kemampuan sulit untuk menghafal. Penekanan menghafal karena target pembelajaran Bahasa Arab pada jenjang kelas 1 MI yang menjadi penekanan adalah menghafal dan langsung dalam kegiatan sehari-hari.

Kondisi ini tentu menyebabkan sebagian anak kurang tertarik dengan bahasa Arab. Oleh karena itu, maka Guru melakukan pendekatan dengan siswa yang kurang tertarik pada Bahasa Arab, salah satunya melalui menceritakan kisah tentang bahasa Arab yang menarik. Salah satunya dengan menceritakan manfaat belajar bahasa Arab maka akan bisa ke Mekkah dan akan mampu berkomunikasi dengan orang Arab asli. Jadi dengan hal tersebut mereka menjadi antusias dan semangat untuk belajar Bahasa Arab.

Terkait denga keterbatasan jam pelajaran yang hanya 2 JP per minggu, hal ini berdampak kepada system pembelajaran yang banyak dilakukan di dalam kelas. Sampai saat ini guru belum mengembangkan model pembelajaran Bahasa Arab yang dilakukan di luar kelas. Untuk meminimalisir kelemahan ini, MI Ar-Rahmah telah membuat program kegiatan ekstrakulikuler language club yang dilaksanakan pada hari Sabtu.

Dari uraian di atas, maka implementasi pembelajaran bahasa Arab dengan pendekatan saintifik yang dilakukan oleh Guru Kelas 1 MI Ar-Rahmah Jabung Malang, masih belum maksimal. Pada satu sisi, guru telah banyak melakukan ragam metode dan media agar anak-anak memiliki kemampuan untuk mengamati, menanya, mencoba, mengasosiasikan, dan mengkomunikasikan. Dalam konteks ini, melalui variasi metode dan penggunaan media yang cukup variatif ${ }^{8}$, guru telah mampu untuk memberikan motivasi kepada anak-anak belajar bahasa

\footnotetext{
${ }^{8}$ Silahkan baca ragam media hasil kajian dari Moh. Mofid, "MENINGKATKAN KETERAMPILAN MEMBACA DENGAN MENGGUNAKAN MEDIA 'POWERPOINT’ UNTUK SISWA KELAS X DI SMA MODERN ALRIFAIE 2 MALANG," Muhadasab: Jurnal Pendidikan Bahasa Arab 2, no. 1 (June 1, 2020): 27-57, http://ejournal.iaiskjmalang.ac.id/index.php/muhad/article/view/150. Mochamad Hasyim and Amang Fathurrohman, "Pengembangan Desain Permainan Stik Lalaran Untuk Peningkatan Kemampuan Mufrodat Dalam Kitab Bahasa Arab Ro'sun Sirah Bagi Santri Madrasah Diniyah Tingkat Ula,” Studi Arab 9, no. 2 (2018): 147-160. Syifaul Qulub and Amang Fathurrohman, "تطوير وسائل تعليم كوميك لترقية مهارة القراعة" Studi Arab 6, no. 2 (December 1, 2015): 99-116, https://jurnal.yudharta.ac.id/v2/index.php/studi-arab/article/view/57.Muhammad Holimi,
} 
Arab dengan menyenangkan. ${ }^{9}$ Namun karena jenang implementasi dalam belajar bahasa Arab masih di kelas 1, maka kemampuan anak masih diarahkan untuk menghafal tema-tema seharihari.

Dengan demikian, maka hal ini relevan dengan kajian Moh. Ainin bahwa belajar bahasa seharusnya juga menggunakan pendekatan bahasa pula. ${ }^{10}$ Apabila pendekatan saintifik ini dipaksanakan, maka pendekatan saintifik ini tidak akan berjalan dengan maksimal.

\section{Kesimpulan}

Implementasi pembelajaran bahasa Arab di kelas 1 MI Ar-Rahmah telah dilakukan dengan menggunakan pendekatan saintifik, yakni siswa dibimbing agar memiliki kemampuan untuk mengamati, menanya, mencoba, mengasosiasikan, dan mengkomunikasikan. Guru ArRahmah telah mengembangkan ragam metode dan memanfaatkan berbagai media dalam proses pembelajaran tersebut. Namun, karena masih kelas 1, maka penekanan bahasa Arab masih diarahkan untuk menghafal mufrodat terkait tema sehari-hari. Sehingga pendekatan saintifik masih belum bisa maksimal untuk diimplementasikan pada anak kelas 1 MI Ar-Rahmah jabung Malang.

Hasil kajian ini merekomendasikan kepada guru untuk menggunakan pendekatan bahasa yang relevan dengan dengan jenjang dan kemampuan peserta didik

\section{Daftar Pustaka}

Abduh, Muhammad. "Interaksi Pada Pendekatan Saintifik (Kajian Teori Scaffolding)." In Prosiding Seminar Nasional Dan Call for Papers Pendidikan 2017 (PGSD UMS \& HDPGSDI Wilayah Jawa), 307-318. Semarang: Program Studi Pendidikan Guru Sekolah Dasar FKIP UMS, 2017.

Ainin, Moh. "IMPLEMENTASI PENDEKATAN SAINTIFIK DI ERA KURIKULUM 13 DALAM PEMBELAJARAN BAHASA ARAB: RELEVANKAH?” In Prosiding Konfererensi Nasional Babasa Arab, 3:377-385. Kota Malang: Sastra Arab Universitas Negeri Malang, 2017.

Hasyim, Mochamad. “ استخدام طريقة جيكسو في تعليم مهارة القر اءة: بحث تجريبي في مدرسة دار التقوى الثنانوية

“PEMBELAJARAN MUFRODAT DENGAN MENGGUNAKAN MEDIA GAMBAR," Muhadasab: Jurnal Pendidikan Babasa Arab 1, no. 1 (June 1, 2019): 86-102,

http://ejournal.iaiskjmalang.ac.id/index.php/muhad/article/view/87.Mochamad Hasyim, " طريقة جيكسو

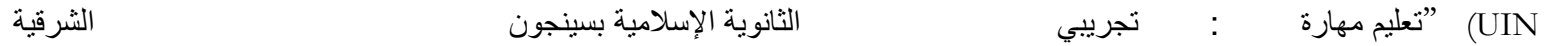

Maulana Malik Ibrahim Malang, 2014), accessed June 10, 2020, http://etheses.uin-malang.ac.id/8217/.

${ }^{9}$ Silahkan baca hasil kajian Sholihatul Atik Hikmawati, "Penerapan Mode Kooperatif Model Teams-Games-

Tournaments (TGT) Untuk Meningkatkan Motivasi Dan Hasil Belajar Maharah Qira’ah Siswa Kelas XII Bahasa MAN Batu," Penerapan Mode Kooperatif Model Teams-Games-Tournaments (TGT) Untuk. Meningkatkan Motivasi Dan Hasil Belajar Mabarah Qira'ah Siswa Kelas XII Bahasa MAN Batu/Sholihatul Atik Hikmawati (Universitas Negeri Malang.

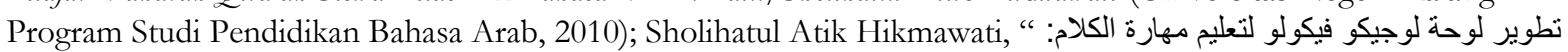
"بحث تطويري وتجريبي في مدرسة ثنائية اللغة الثانوية الإسلامية باتو جاوى الثرقية (Universitas Islam Negeri Maulana Malik Ibrahim, 2013).

${ }^{10}$ Ainin, "IMPLEMENTASI PENDEKATAN SAINTIFIK DI ERA KURIKULUM 13 DALAM PEMBELAJARAN BAHASA ARAB: RELEVANKAH?” 
42 | Volume 11, Nomor 1, Juni 2020

الإسلامية بسينجون اجونج بورو اساري باسوروان جاوى الثرقية. UIN Maulana Malik Ibrahim Malang, 2014. Accessed June 10, 2020. http://etheses.uin-malang.ac.id/8217/.

Hasyim, Mochamad, and Amang Fathurrohman. "Pengembangan Desain Permainan Stik Lalaran Untuk Peningkatan Kemampuan Mufrodat Dalam Kitab Bahasa Arab Ro’sun Sirah Bagi Santri Madrasah Diniyah Tingkat Ula." Studi Arab 9, no. 2 (2018): 147-160.

Hikmawati, Sholihatul Atik. "PENDEKATAN DAN MODEL-MODEL PENGEMBANGAN KURIKULUM BAHASA ARAB PADA MADRASAH/SEKOLAH DI INDONESIA.” Muhadasab: Jurnal Pendidikan Bahasa Arab 2, no. 1 (2019): 203-218.

- "Penerapan Mode Kooperatif Model Teams-Games-Tournaments (TGT) Untuk Meningkatkan Motivasi Dan Hasil Belajar Maharah Qira’ah Siswa Kelas XII Bahasa MAN Batu.” Penerapan Mode Kooperatif Model Teams-Games-Tournaments (TGT) Untuk. Meningkatkan Motivasi Dan Hasil Belajar Maharah Qira'ah Siswa Kelas XII Bahasa MAN Batu/Sholihatul Atik. Hikmawati. Universitas Negeri Malang. Program Studi Pendidikan Bahasa Arab, 2010.

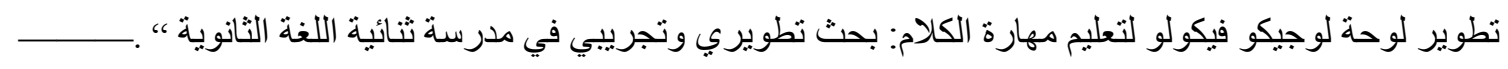
.الإسلامبة بانو جاوى الثرقية.” Universitas Islam Negeri Maulana Malik Ibrahim, 2013.

Holimi, Muhammad. "PEMBELAJARAN MUFRODAT DENGAN MENGGUNAKAN MEDIA GAMBAR." Mubadasah: Jurnal Pendidikan Babasa Arab 1, no. 1 (June 1, 2019): 86-102. http://ejournal.iaiskjmalang.ac.id/index.php/muhad/article/view/87.

Menteri Pendidikan dan Kebudayaan Republik Indonesia. Peraturan Kementrian Pendidikan Dan Kebudayaan No. 103 Tabun 2014 Tentang Pembelajaran Pada Pendidikan Dasar Dan Menengah. Indonesia, 2014.

Mofid, Moh. "MENINGKATKAN KETERAMPILAN MEMBACA DENGAN MENGGUNAKAN MEDIA ‘POWERPOINT’ UNTUK SISWA KELAS X DI SMA MODERN AL-RIFAIE 2

MALANG." Mubadasab: Jurnal Pendidikan Bahasa Arab 2, no. 1 (June 1, 2020): 27-57.

http://ejournal.iaiskjmalang.ac.id/index.php/muhad/article/view/150.

Qulub, Syifaul, and Amang Fathurrohman. “تطوير وسائل تعليم كوميك لترقية مهارة القراءة/1udi Arab 6, no. 2 (December 1, 2015): 99-116. https://jurnal.yudharta.ac.id/v2/index.php/studi$\mathrm{arab} / \mathrm{article} / \mathrm{view} / 57$.

Reiser, Brian J. "Scaffolding Complex Learning: The Mechanisms of Structuring and Problematizing Student Work." The Journal of the Learning sciences 13, no. 3 (2004): 273-304. 